\title{
Effect of Nano Titanium Oxide Addition on Color Stability on Two Types of Maxillofacial Silicone Materials
}

\author{
Dhuha A. Shakir ${ }^{1}$, B.D.S. ${ }^{2}$, Faiza M. Abdul-Ameer ${ }^{3}$, B.D.S, M.Sc. ${ }^{4}$ \\ ${ }^{1,2}$ Master student, Department of Prosthodontics, College of Dentistry, University of Baghdad. \\ ${ }^{3,4}$ Assistant professor, Department of Prosthodontics, College of Dentistry, University of Baghdad.
}

\begin{abstract}
Background: After 4-14 months of clinical use silicone elastomers may subjected for degradation, despite of they have a desirable properties like, easy coloration, easy manipulation, and biocompatibility. The purpose of this study: was to evaluate the effect of addition $\mathrm{TiO}_{2}$ nanofiller on thecolor stability of VST50F (RTV) and Cosmesil M511(HTV) maxillofacial silicone elastomer. Materials and methods: 60 samples were fabricated by addition of $0.25 w t \% \mathrm{TiO}_{2}$ nanofiller with 0.25 wt.\% of intrinsic pigment (cream) for VST5OF and $0.2 \mathrm{wt} \%$ of nano $\mathrm{TiO}_{2}$ with $0.25 \mathrm{wt} . \%$ of intrinsic pigment (cream) for M511 maxillofacial silicone elastomer. According to pilot study, $0.25 \mathrm{wt} \%$ and $0.2 \mathrm{wt} \%$ of nano $\mathrm{TiO}_{2}$ with $0.25 \mathrm{wt} . \%$ intrinsic pigment reinforcement revealed superior properties (tear strength, and hardness shore A). The main study samples were divided into three (3) groups for both silicone material, which wrer divided into (A: control pure silicone without nano $\mathrm{TiO}_{2}, \mathrm{~B}$ : silicone incorporated with nano $\mathrm{TiO}_{2}$ and $\mathrm{C}$; silicone incorporated with nano $\mathrm{TiO}_{2}$ and intinsic pigment )each group contains (10) samples, then each group was tested by: vita easy shade test and spectrophotometer test.The samples were tested before and after artificial ageing and the data were analyzed with a descriptive statistical analysis, three -way ANOVA. Results: The addition of $0.25 w t \%$ of $\mathrm{TiO}_{2}$ nanofiller into VST50F maxillofacial elastomer and $0.2 w t \%$ of $\mathrm{TiO}_{2}$ nanofiller into comensil M511and the addition of intrinsic pigment with nano $\mathrm{TiO}_{2}$ resulted in a highly increase in mean values of the color change, after subjected to artifacial ageing for both silicone elastomer materials. $\underline{C o n c l u s i o n}^{\text {Reinforcement of nano TiO }}{ }_{2}$ with specific concentrations for each VST50F and Cosmesil M511 maxillofacial silicone materials were increase the service life of the prosthesis, but did not protect the silicone matrix from artificial aging degradationof both VST50F and Cosmesil M511 maxillofacial silicone materials.
\end{abstract}

Keywords: Maxillofacial silicone elastomer, VST50F silicone elastomer, Cosmesil M511silicone elastomer, nano $\mathrm{TiO}_{2}$, intrinsic pigments, artifical ageing

\section{Introduction}

Surgical reconstruction may not be possible owing to size or location of the facial disfigurement can be the result of a congenital anomaly, trauma or tumor surgery, The patient's medical condition or personal desires may also preclude reconstructive surgery. In such cases, prosthetic rehabilitation is indicated ${ }^{(1)}$. As a natural need of human to repair or hide their facial defect maxillofacial prostheses were introduced. It is a skill and the knowledge of cosmetical, anatomics and restore function which is enquire through synthetic substitution of craniofacial structures that are missing or defective due to oncological surgery, facial trauma or congenital and developmental anomalies ${ }^{(2)}$.

In the past several materials have been utilized to fabricate maxillofacial prosthesis include wood, wax, ivory, metal and recently polymers such as silicone elastomer, polyurethane elastomers, and acrylic resins ${ }^{(3)}$.

For manufacturing maxillofacial prosthesis silicone elastomer has been utilized as the material of decision since the introduction of it by Barnhart in 1960, because of its chemical inertness, durability, ease of manipulation and biocompatibility ${ }^{(4,5,6)}$.

The most common reason for refabrication is the expected half-life of silicone maxillofacial prosthesis and degradation of color and mechanical properties of the prosthesis ${ }^{(7)}$. Some unpleasant property of silicone elastomer material; the most important one has small tear and tensile strength, deficient elasticity and degradation of physical and color properties ${ }^{(8)}$.

\section{Materials and Methods}

Two types of maxillofacial silicone elastomers had been used, room temperature vulcanized VST50F RTV (Factor II Inc., USA) and heat temperature vulcanized Cosmesil M511 HTV (Factor II Inc., USA), nano titanium oxide particles $\left(\mathrm{TiO}_{2}\right)$ (Sky spring nano materials, Inc., USA), cream pigment (functional intrinsic FI) (Factor II Inc., Lakeside, USA) incorporated into each materials with selected concentration according to pilot study. About 60 specimens were prepared: 30 specimens for RTV silicone elastomer material and others 30 specimens for HTV silicone elastomer material that shared into 3 groups according to the conducted test with 10 specimens for each group that divided into (A, B, and C) . Group (A) include control group without nano $\mathrm{TiO}_{2}$, group (B) silicone material incorporated with nano $\mathrm{TiO}_{2}$ and group (C) silicone material incorporated with nano $\mathrm{TiO}_{2}$ and intrinsic pigment.

\section{Pilot study}

A pilot study was made to determine the best concentration for nano $\mathrm{TiO}_{2}$ and intrinsic pigment to be used in the main study by testing its effect on tear strength and hardness. For RTV silicone elastomer the best concentration of nano $\mathrm{TiO}_{2}$ was 0.25 wt.\% concentration and for intrinsic pigment 0.25 wt.\% concentration, while for HTV silicone elastomer nano

\section{Volume 6 Issue 12, December 2017}




\section{International Journal of Science and Research (IJSR) \\ ISSN (Online): 2319-7064 \\ Index Copernicus Value (2016): 79.57 | Impact Factor (2015): 6.391}

$\mathrm{TiO}_{2}$ was 0.2 wt. $\%$ concentration and for intrinsic pigment was 0.25 wt. $\%$ concentration.

\section{Mold making}

Specimens dimensions were designed by use Auto CAD 2013( Autodesk Inc, San Rafael, CA, USA) then processed utilizing computer numerical control machine to form the matrix part of the mold that the material was poured into it $^{(\mathbf{9})}$ (Figures 1and Figure 2).

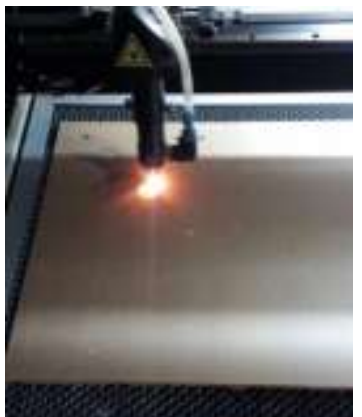

Figure 1: Acrylic mold for RTV silicone material.

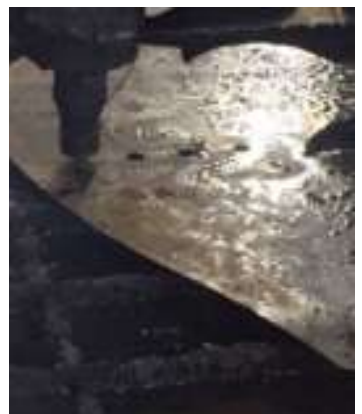

Figure 2: Metal mold for HTV silicone material.

\section{Mixing of the silicone base with nanoTiO}

As recommended by manufacturer's instructions the mixing of VST50F and Cosmesil M511 silicone elastomers were in a proportion 10:1 of the base and catalyst for VST50F, and the base with thinner for Cosmesil M511.NanoTiO 2 and intrinsic pigment were hand-mixed with the base for 1 minute \pm 1 second by a clean stiff flat ended spatula followed for 2 minutes \pm 1 second mixing by a mechanical mixer in a mixer container without vacuum ${ }^{10,11}$, then mixing for 7 minutes \pm 1 second by a mechanical mixer with vacuum to prevent air bubbles formation.$^{(12)}$ The vacuum pressure was 28 inches $\mathrm{Hg}$ as recommended by the manufacturer ${ }^{(13)}$. Before adding catalyst, the mixture was left for 2 minutes because the rotation of the mixer create heat and this lead to decrease the working time of the material according to pilot study and other studies ${ }^{(14)}$.

\section{Adding the catalyst}

Mixing of the base and catalyst for RTV silicone elastomer and mixing of the base with thinner for HTV silicone elastomer were made at $50 \pm 10 \% \mathrm{RH}$ (relative humidity) and $23 \pm 2{ }^{\circ} \mathrm{C}$ (controlled temperature). A metal spatula of flat ended was used for mixing the base with catalyst or thinner recommended by the manufacturer. The base and catalyst or thinner were mixed by mechanical mixer with vacuum for 5 minute \pm 5 second in order to remove all the air bubbles entrapped during mixing with the catalyst, the mixing was done by the same operator in one direction ${ }^{(10,15,16)}$. Then pouring the mixture into syringe to be ready for injected into the molds.

\section{Pouring the mixture into the molds}

The matrix and the bottom parts and the cover of the mold were previously coated with petroleum jelly ${ }^{(12,16)}$ for HTV silicone elastomer molds and separating medium for RTV silicone elastomer molds, then the matrix parts and bottom parts were securely attached for the two types molds (metal molds for HTV silicone elastomer and acrylic molds for RTV silicone elastomer) and placed on the vibrator for RTV silicone elastomer with the mold spaces coated with separating medium The material was injected from the syringe into the mold and a cover (RTV silicone molds) and a glass slab (HTV silicone molds), was laid onto the matrix filled with the material. Lying of the cover part, the glass slab was started from one side by resting the bottom edge of the slab and holding the topedge, while the covers, the glass slab was carefully and slowly lowered onto matrix to force excess material and air out ahead of it. Then a constant load of $(1 \mathrm{Kg})$ was placed over the acrylic molds to ensure that all bubbles were disappeared (Figure 3), after that remove the load and tight the molds securely with nuts and G-clamps and left it for setting $(2-4 \mathrm{hrs})$ as recommended by manufacturer's instructions, while for the metal molds after the glass slab was laid the molds were tightly secured with nuts and apply a constant load $(1 \mathrm{Kg})$ over it and placed into hot dry oven (Figure 4).

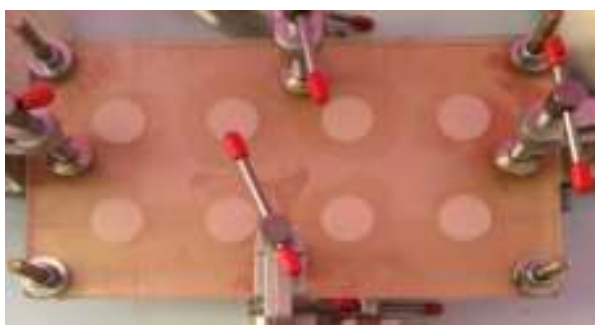

Figure 3: Pressure applied over the cover mold and closure with nuts and G-clamps.

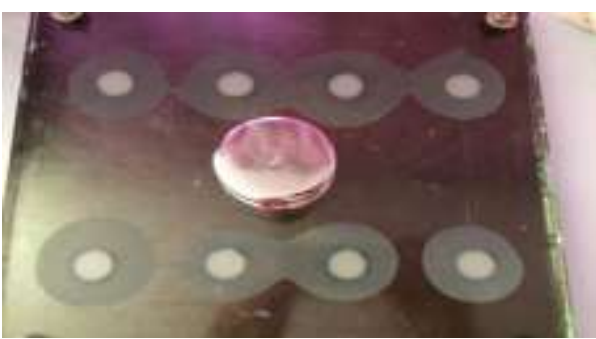

Figure 4: Pressure applied over the cover mold and closure with nuts and G-clamps

\section{Demolding and storage of samples}

According to manufacturer's product description the RTV silicone elastomer material sets in about 2-4 hrs. and for HTV silicone elastomer material sets in hot dry oven for one $\mathrm{hr}$, then the samples were removed carefully from the mold ${ }^{(18)}$.Samples that had visible defects (to the same operator) were discarded before testing ${ }^{(19)}$. The samples were stored in a custom-made lightproof box in an air-conditioned room. During storage, the temperature was $10-30^{\circ} \mathrm{C}$ and $\mathrm{RH}$ did not excess $80 \%{ }^{(20)}$.

\section{Volume 6 Issue 12, December 2017}




\section{International Journal of Science and Research (IJSR) \\ ISSN (Online): 2319-7064 \\ Index Copernicus Value (2016): 79.57 | Impact Factor (2015): 6.391}

\section{Conditioning of samples}

Samples were conditioned for 24 hours prior to testing ${ }^{(21)}$. Then, samples were conditioned at a standard laboratory temperature of $23 \pm 2^{\circ} \mathrm{C}$ for a minimum of 3 hours after removal of flash ${ }^{(43)}$. The flash was removed with a scalpel and sharp surgical blade \# $11^{\text {(12) }}$.

\section{Physical testing procedure}

\section{Vita easy shade test}

The samples were subjected to initilized chromatic analysis through a Visible Ultraviolet Reflection Spectrophotometer. The CIE L*a*b* system was used for calculating the color alterations, constitute by the "Commission Internationale de l' Eclairage - CIE". This system permits the rate of $\Delta \mathrm{E}$ (color variation) in the middle of two scanning to be measured through the formula:

$\Delta \mathrm{E}=\left[(\Delta \mathrm{L})^{2}+(\Delta \mathrm{a})^{2}+(\Delta \mathrm{b})^{2}\right]$

\section{Spectrophotometer light transmission test}

The amount of light transmitted through the sample was measured by using a spectrophotometer as a function of wavelength. The sample was located over the light opening of the device and then subjected to light. The percentage and the reading of transmitted light, was then acquired from the screen of the computer attached with the device.

\section{Artificial aging}

After measuring the color alteration and the amount of light transmission of the samples with vita test and spectrophotometer test The samples were assessed in Weather-Ometer device (QUV) model (Xenon Arc Ci4000, Atlas Material Testing Technology, USA) .According to the most popular aging standardization ASTM G-154 under cycle $7\left({ }^{13)}\right.$. This cycle is primarily exposing the samples to cycles of (5) hours of UVA light source at $340 \mathrm{~nm}$ with high temperature of $60^{\circ} \mathrm{C}$, then followed by 4 hours (spray for $0: 15$ minutes) and condensation (dew) at $50^{\circ} \mathrm{C}$ for $3: 45$ minutes

\section{Statistical analyses}

For analyzing the data of this study the statistical package for the social science software (version 23) (SPSS) was used, and the statistics below were performed:

1) Descriptive statistic: Graphical display by bar chart.

2) Inferential statistic: Two-way ANOVA (Two-way analysis of variance) and MC (Multiple Comparison) as a post-hoc were used with these significance levels:

$\mathrm{P}>0.05$ NS Non- significant

$0.05 \geq \mathrm{P}>0.01 \mathrm{~S}$ Significant

$\mathrm{P} \leq 0.01$ HS Highly significant

\section{Results}

The mean value of color change for RTV is higher than mean value ofcolor change for HTV before and after artificial aging and there is highly significant change of color when compare each time period with other period $(\mathrm{p}<$ 0.01 ). Result found that there is highly significant change of color with time (color decrease when the time increase) $(\mathrm{p}<$ 0.01 ) for each group with test at material.

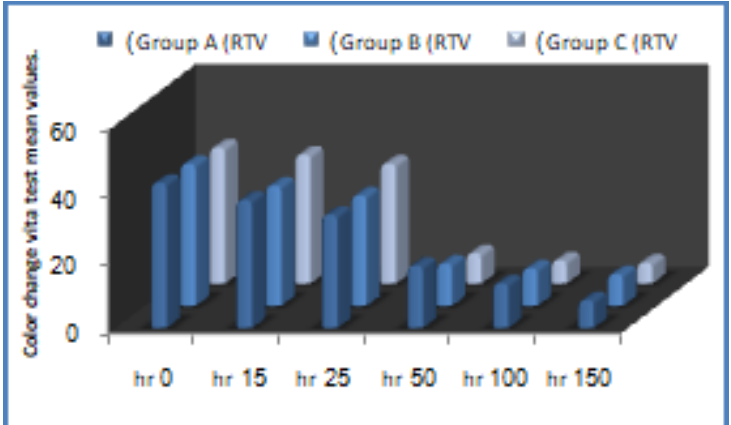

Figure 5: Bar chart of color change vita test mean values of all groups for RTV

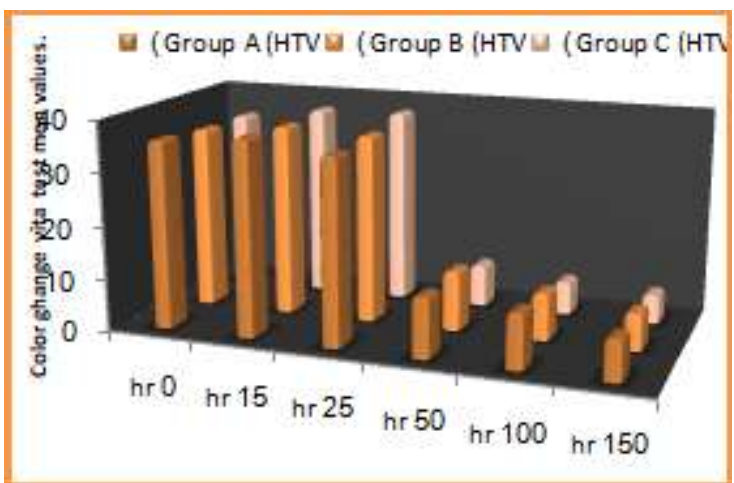

Figure 6: Bar chart of color change vita test mean values of all groups for HTV

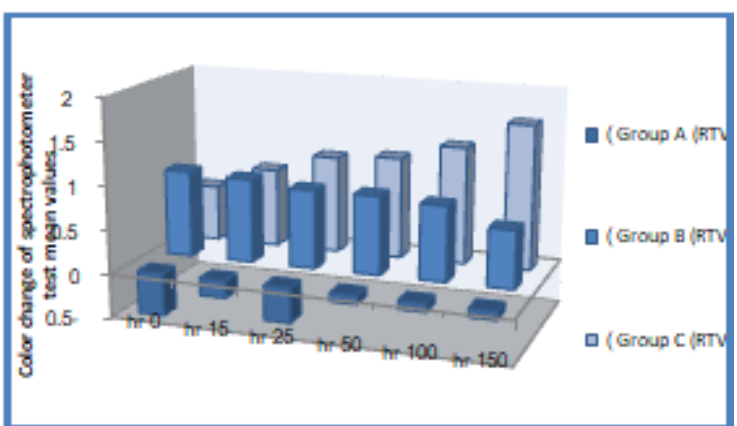

Figure 7: Bar chart of color change spectro test mean values of all groups for RTV.

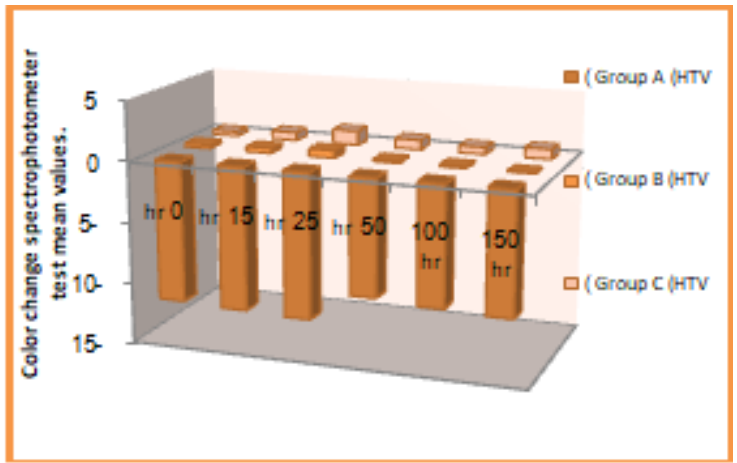

Figure 8: Bar chart of color change spectro test mean values of all groups for HTV. 


\section{International Journal of Science and Research (IJSR) \\ ISSN (Online): 2319-7064}

Index Copernicus Value (2016): 79.57 | Impact Factor (2015): 6.391

Table 1: Descriptive statistics of color change results 3-way ANOVA repeated measure of color change arrange material, test ,groups and times A, RTV material and B, HTV material

A. RTV material

\begin{tabular}{|c|c|c|c|c|c|c|c|c|c|c|c|c|c|c|}
\hline \multirow{2}{*}{ Ma. } & \multirow{2}{*}{ Test } & \multirow{2}{*}{ Gr. } & \multicolumn{2}{|c|}{ Control } & \multicolumn{2}{|c|}{$15 \mathrm{hr}$} & \multicolumn{2}{|c|}{$25 \mathrm{hr}$} & \multicolumn{2}{|c|}{$50 \mathrm{hr}$} & \multicolumn{2}{|c|}{$100 \mathrm{hr}$} & \multicolumn{2}{|c|}{$150 \mathrm{hr}$} \\
\hline & & & M & $\pm \mathrm{SD}$ & M & $\pm \mathrm{SD}$ & M & $\pm \mathrm{SD}$ & M & $\pm \mathrm{SD}$ & M & $\pm \mathrm{SD}$ & M & $\pm \mathrm{SD}$ \\
\hline \multirow{3}{*}{ RTV } & \multirow{3}{*}{ VT. } & $\mathrm{A}$ & 42.78 & 1.864 & 37.74 & .493 & 33.36 & .171 & 18.27 & 3.155 & 13.06 & 1.246 & 8.12 & .193 \\
\hline & & $\mathrm{B}$ & 41.84 & .654 & 35.41 & .486 & 32.52 & .432 & 12.40 & .279 & 10.93 & .558 & 9.24 & .246 \\
\hline & & $\mathrm{C}$ & 40.14 & 1.162 & 38.02 & .282 & 35.37 & .362 & 8.87 & .501 & 6.75 & .445 & 6.10 & .200 \\
\hline \multirow{3}{*}{ RTV } & \multirow{3}{*}{ ST. } & $\bar{A}$ & -.05 & .071 & -.02 & .018 & -.04 & .000 & -.01 & .000 & -.01 & .000 & -.01 & .000 \\
\hline & & $\mathrm{B}$ & .99 & .001 & .96 & .002 & .90 & .001 & .90 & .001 & .86 & .001 & .66 & .001 \\
\hline & & $\mathrm{C}$ & .64 & .001 & .90 & .002 & 1.11 & .001 & 1.16 & .001 & 1.34 & .003 & 1.65 & .001 \\
\hline
\end{tabular}

\section{B. HTV material}

\begin{tabular}{|c|c|c|c|c|c|c|c|c|c|c|c|c|c|c|}
\hline \multirow{3}{*}{ HTV } & \multirow{3}{*}{ VT. } & A & 36.03 & 3.048 & 37.45 & .227 & 35.48 & .421 & 11.55 & 1.483 & 10.49 & 1.787 & 7.85 & .690 \\
\hline & & B & 35.00 & 1.191 & 36.57 & .275 & 35.91 & .841 & 11.43 & .395 & 8.99 & .260 & 7.13 & .116 \\
\hline & & $\mathrm{C}$ & 34.80 & 1.012 & 36.99 & .202 & 37.35 & .458 & 8.02 & .175 & 6.37 & .368 & 5.56 & .255 \\
\hline \multirow{3}{*}{ HTV } & \multirow{3}{*}{ ST. } & $\mathrm{A}$ & -11.59 & .027 & -11.79 & .009 & -11.96 & .055 & -9.61 & .008 & -9.90 & .011 & -10.09 & .016 \\
\hline & & B & .29 & .001 & .41 & .001 & .61 & .002 & .18 & .001 & .15 & .001 & .06 & .001 \\
\hline & & $\mathrm{C}$ & .37 & .002 & .67 & .002 & 1.16 & .001 & .79 & .001 & .59 & .001 & .82 & .001 \\
\hline
\end{tabular}

\section{Discussion}

The aesthetic restoration and reestablishment of self-esteem of mutilated patients is the main objective of prosthetic rehabilitation of facial defects ${ }^{(14)}$. Color is the most important parameter utilized by patient in the assessment of facial prostheses. Change in color is one of the requests of substitution, which regrettably occurs due to aging process, use of disinfectants or additives ${ }^{(15 ; 16 ; 17)}$.

The primary physical property studies of maxillofacial elastomers are the color stability which acts as a part of these studies. General degradation of polymers result from aging and environmental factors that effect on the silicone elastomer, which cause changes in color itself, and in several cases cause color changes of the pigments. Alteration in chemical and physical characteristics can occur from the weathering of polymers, which cause alteration in their mechanical properties. The main source for most polymeric materials deterioration is the integration activity of oxygen and sunlight, photo-oxidative attack, on their chemical structure $^{(18,19.20)}$.

Hatamleh et al., in $\mathbf{2 0 1 1}^{21}$ showed that silicone elastomer stored for 6 months in a dark environment get a little decreased initial performance, than the silicone exposed to the surrounding environment presented a sharp decline in properties. Temperature, light, and mechanical force are the common factors that affect in the performance of silicone elastomer materials.

According to the results obtained in this study, color instability occurs both VST50F and Cosmesil M511, whether pigmented or not, presented $(\Delta \mathrm{E}>0)$, regardless of the senescent stage. It is recognized that both intrinsic and extrinsic factors may be caused chromatic alteration ${ }^{(22)}$. The discoloration of the material itself result from intrinsic factors involve with alterations in the matrix ${ }^{(23)}$. While the absorption and adsorption of substances represent extrinsic factors, also cause discoloration ${ }^{(24)}$. Other factors correlated with this, can produce color insecurity, such as accumulation of stains, surface roughness, dehydration, water absorption, infiltration, degradation from use, chemical degradation, , oxidation during double carbon reactions to produce peroxide compounds, and continuous formation of pigments due to degradation of products ${ }^{(25)}$.

The vita easy shade test show that the last value of color changes following 150 hours of senescent for VST50F and Cosmesil M511 maxillofacial silicone elastomers were got by the colored test specimens (group C) and the highest value was obtained by group B for VST50F and by group A for Cosmesil M511 (Table 1). The spectrophotometric analysis revealed that the lowest values of color changes after 150 hours of aging for VST50F and Cosmesil M511 were got by the un-pigmented test specimens (group A) (Table 1).

For materials VST50F silicone elastomer revealed that the highest mean value of color change than CosmesilM511 maxillofacial silicone elastomers because of the curing procedure of Cosmesil M511subjected to heat for setting and when subjected to artificial aging exposed for more heat and humidity which may be increase the color change of it.

For tests vita easy shade test show the highest mean value of color change than spectrophotometer test this could be due to the procedure of vita device differ from the spectrophotometer which measure $a^{*} b * L$ that represent (Hue, chroma and value of color) while the spectrophotometer device measure the translucency of substances that permits the passage of light but disperses the light, so objects cannot be seen through the material. There are many variables include filler types, size and amount that may affect the translucency of a material ${ }^{(26 ; 27)}$.

Increasing filler load leads to a denser filler-filler network within the polymer matrix. Fillers tend to fill any spaces or voids within the polymer. As some of the light may be partly reflected and some may be absorbed, this represent effects of how light interact with the polymer, as a result reducing the amount of light transmitted ${ }^{(28)}$.

Reduction of light transmission may be recognized to the scattering effect of nano $\mathrm{TiO} 2$ filler. Because the index of refraction of nano $\mathrm{TiO} 2$ is different from that of silicone 


\section{International Journal of Science and Research (IJSR) \\ ISSN (Online): 2319-7064}

Index Copernicus Value (2016): 79.57 | Impact Factor (2015): 6.391

elastomer light scattering occurs. The scattering effect will cause the material appear more dark ${ }^{(29 ; 30)}$.

Result indicates that both VST50F and Cosmesil M511 introduce acceptable color solidity and are suggested for clinic use because the accelerated ageing of UV, which was carried out for 24,48 , and 72 hours, is approximately equal to $0.5,1$ and 1.5 years of clinical wear, respectively ${ }^{(31 ; 32)}$. This results were agree with other study ${ }^{(33 ; 34 ; 35 ; 3 ; 36)}$. And according to the addition of pigments some physical and mechanical property, such as color stability, may be modify. For mixing groups, group B presented the highest color alteration values and group $\mathrm{C}$ presented the lowest values for vita easy shade test of both VST50F and Cosmesil M511because of the silicones materials comprising pigments of yellow, orange yellow, white or light orange exhibited the largest color modification when subjected to accelerate ageing, which leads to loss of the color ${ }^{(37)}$. While for spectrophotometer test group $\mathrm{C}$ presented the highest values and group B show the lowest values (Figures 5, 6, 7 and 8). This would be depending on the dimension particle add ion or even to senescent. Also the cohesive energy of silicone was a low and, for that reason, a weak molecular interaction. So, mini subatomic lean towards aggregation, while the bigger ones detached from the polymeric, and do not back to the augmentation of the materials ${ }^{(38)}$. Also because of scattering activity of nanoTiO2 that reduce the light transmission and make the material appear dark.

The highest mean value of color change for group A of VST50F maxillofacial silicone elastomer in vita test than the other two groups in all period of time this is due to non colored silicone itself, color modification occur with time and even without subjection to UV irradiation ${ }^{(7)}$ except in the time period $(150 \mathrm{hr}$.) the group B have the highest mean value than other two groups with highly significant difference. Because of the strong ability of nano-TiO2 to resist UV rays. And due to their refractive index and optical activity that, can absorb, reflect and scatter UV rays $(39 ; 40 ; 41$; 42). So, modification of silicone elastomer material with $\mathrm{TiO} 2$ nanoparticles can also improve resistance to environmental UV irradiation. The highest mean value of color change of group C for Cosmesil M511 maxillofacial silicone elastomer of spectrophotometer test than the other two groups. According to (Haug et al., in 1999) ${ }^{7}$ accomplished that the effect of weathering on color can be altered by the addition of pigments. The addition of inorganic pigment had the best color stability.

\section{Refrences}

[1] Maller US, Karthik KS and Maller SV. "Maxillofacial Prosthetic Materials - Past and Present Trends." J Ind Aca Dent Spec 1, 2010; (2): 42-44.

[2] Khan Z., Gettleman L., Jacobson C, 1992. "Conference report: materials research in maxillofacial prosthetics." J Dent Res 71:1541-2.

[3] Andres CJ, Haug SP, Munoz CA and Bernal G. "Effects of environmental factors on maxillofacial elastomers: Part I-Literature review.” J Prosthet Dent,1992; 68(2): 327-330.

[4] Barnhart GW. "A new material and technic in the art of somatoprosthesis."J Dent Res, 1960; 39: 836-844.
[5] Andres CJ, Haug SP, Brown DT and Bernal G. "Effects of environmental factors on maxillofacial elastomers: Part II--Report of survey." J Prosthet Dent, 1992b; 68(3): 519-522.

[6] Aziz, T., Waters, M., Jagger, R. "Analysis of the properties of silicone rubber maxillofacial prosthetic materials". J Dent, 2003a.; 31, 67-74.

[7] Haug, S.P., Andres, C.J., Moore, B.K,. "Color stability and colorant effect on maxillofacial elastomers. Part I: colorant effect on physical properties". J Prosthet Dent1999, ; 81, 418-422.

[8] Aziz, T., Waters, M., Jagger, R. "Development of a new poly (dimethylsiloxane) maxillofacial prosthetic material". J Biomed Mater Res, ., 2003b, Part B; 65, 252-261.

[9] Chi, Y.H. "Effect of Silica Filler on the Mechanical Properties of Silicone Maxillofacial Prothesis". M.Sc. Thesis, School of Dentistry, Indiana University, 2014.

[10] Guiotti A.M., Goiato M.C., Dos Santos D.M., VechiatoFilho, A.J. "Comparison of conventional and plantextract disinfectant solution on the hardness and color stability of a maxillofacial elastomer after artificial weathering".prosthet Dent J , 2015; 48:4-13.

[11]Han, Y., Powers, J.M., Kiat-amnuay, S.. "Effect of opacifiers and UV absorbers on pigmented maxillofacial silicone elastomer, part 1: Color stability after artificial aging". J Prosthet Dent, 2013; 109, $397-$ 401.

[12]Zayed, S., Alshimy, A., Fahmy, A. "Effect of surface treated silicon dioxide nanoparticles on some mechanical properties of maxillofacial silicone elastomer". Int J Biomater, 2014; 2014, 750398-750405.

[13] ASTM G 154 cycle 7 UV Testing Lab. http://www.CasCadeTEK.Com 2015.

[14] Goiato, M.C., Pesqueira, A.A., Ramos da Silva, C., Gennari Filho, H., Micheline dos Santos, D., 2009a. "Patient satisfaction with maxillofacial prosthesis. Literature review". JPRAS; 62, 175-180.

[15] Tran NH, Scarbecz M and Gary JJ. "In vitro evaluation of color change in maxillofacial elastomer through the use of an ultraviolet light absorber and a hindered amine light stabilizer." J Prosthet Dent , 2004; 91(5): 483-490.

[16] Goiato, M.C., Pesqueira, A.A., Santos, D.M. dos, Dekon, S.F. de C., 2009b. "Evaluation of hardness and surface roughness of two maxillofacial silicones following disinfection". Braz Oral Res; 23, 49-53.

[17] Mancuso DN, Goiato MC, and Santos DM. "Color stability after accelerated aging of two silicones, pigmented or not,for use in facial prostheses." Braz Oral Res, 2009a; 23: 144-48.

[18] Dootz ER, Koran A, 3rd, Craig RG. "Physical properties of three maxillofacial materials as a function of accelerated aging. " J Prosthet Dent, 1994 ;71:379_ 383.

[19]Davis A, Sims D. "Weathering of polymers. London: Applied Science Publishers." pp., 1983; 1-41.

[20] Gijsman P, Hennekens J, Janssen K. "Comparison of UV degradation chemistry in accelerated (xenon) aging tests and outdoor tests (II) Polym Degrad Stab." , 1994; 46:63-74.

[21] Hatamleh, M.M., Polyzois, G.L., Silikas, N., Watts, D.C. "Effect of extraoral aging conditions on

\section{Volume 6 Issue 12, December 2017}




\section{International Journal of Science and Research (IJSR) \\ ISSN (Online): 2319-7064 \\ Index Copernicus Value (2016): 79.57 | Impact Factor (2015): 6.391}

mechanical properties of maxillofacial silicone elastomer". J Prosthodontics., 2011; 20, 439-446.

[22] Villalta P, Lu H, Okte Z, Garcia-Godoy F, Powers JM. "Effects of staining and bleaching on color change of dental composite resins." J Prosthet Dent, 2006; 95(2):137-42.22.

[23] Wilson NH, Burke FJ, Mjor IA. "Reasons for placement and replacement of restorations of direct restorative materials by a selected group of practitioners in the United Kingdom." Quintessence Int, 1997.; 28(4):2458.

[24] Satou N, Khan AM, Matsumae I, Satou J, Shintani H, 1989. "In vitro color change of composite-based resins." Dent Mater.; 5(6):384-7.

[25] Anil N, Hekimoglu C, Sahin S. "Color stability of heatpolymerized and autopolymerized soft denture liners." J Prosthet Dent, 1999; 81(4):481-4.

[26] Lee YK. "Influence of filler on the difference between the transmitted and reflected colors of experimental resin composites." Dent Mater , 2008; 24(9):1243-1247.

[27] Sakaguchi, R.L., Powers, J.M. "Craig's restorative dental materials". Elsevier Health Sciences., 2012.

[28] Mousavinasab SM. "Effects of Filler Content on Mechanical and Optical Properties of Dental Composite Resin in Metal, Ceramic and Polymeric Composites for Various Uses, 1st ed., InTech." , 2011.

[29] Mitra SB, Wu D and Holmes BN. "An application of nanotechnology in advanced dental materials." J Am Dent Assoc , 2003; 134(10): 1382-1390.

[30] Garoushi S, Vallittu PK and Lassila L. "Effect of Short Fiber Fillers on the Optical Properties of Composite Resins." J Mater Sci Res, 2012; 1(2): 174-180.

[31] Takahashi JMFK, Consani RLX, Henriques GEP, de ArrudaNóbilo MA, Mesquita MF. "Effect of accelerated aging on permanent deformation and tensile bond strength of autopolymerizing soft denture liners". Journal of Prosthodontics., 2011; 20:200-4.

[32] Ribeiro Pinto JR, Mesquita MF, de Arruda Nóbilo MA, Elias Pessanha Henriques G. "Evaluation of varying amounts of thermal cycling on bond strength and permanent deformation of two resilient denture liners". Journal of Prosthetic Dentistry; ., 2004; 92:288-93.

[33] Kiat-Amnuay S, Mekayarajjananonth T, Powers JM, Chambers MS, Lemon JC. "Interactions of pigments and opacifiers on color stability of MDX4-4210 type A maxillofacial elastomers subjected to artificial aging." J Prosthet Dent. , 2006;95(3):249-57.

[34] Yu R, Koran III A, Craig RG. "Physical properties of maxillofacial elastomers under conditions of accelerated aging." J Dent Res. , 1980; 59(6):1041-7.

[35] Craig RG, Koran A, Yu R. "Physical properties of a pigmented silicone maxillofacial material as a function of accelerated aging." J Dent Res. , 1980 ; 59(7): 866871.

[36]Lewis DH, Castleberry DJ."An assessment of recent advances in external maxillofacial materials". J Prosthet Dent, 1980.; 43(4):426-32.

[37] Craig RG, Koran A, Yu R, Spencer J."Color stability of elastomers for maxillofacial appliances". J Dent Res., 1978.; 57:866-871.

[38] Anusavice KJ. "Phillips' science of dental materials. 11th ed. St. Louis: Elsevier. ", 2003.
[39] Bajaj P, Babu GN, Khanna DN, Varshney SK. "Room temperature-vulcanized silicone elastomer: effect of curing conditions and the nature of filler on mechanical and thermal properties". J Applied Polymer Science, 1979; 23:3505-14.

[40] Balachandran K, Venckatesh R, Sivaraj R. "Synthesis of nanoTiO2-SiO2 composite using sol-gel method: effect on size,surface morphology and thermal stability". International Journal of Engineering Science and Technology, 2010; 2:3695-700.

[41] Chatterjee A. "Properties improvement of PMMA using nanoTiO2". J Applied Polymer Science, 2010; 118:2890-7.

[42] Stathi, K., Tarantili, P.A., Polyzois, G. "The effect of accelerated ageing on performance properties of addition type silicone biomaterials". J Mater Sci Mater Med., 2010; 21, 1403-1411.

[43] ASTM D1349. "Standard Temperature for Testing". ASTM International, West Conshohocken, PA, 2014.

Volume 6 Issue 12, December 2017 www.ijsr.net 